\title{
Política regional brasileira: retrospectiva e novos rumos
}

\author{
Adriana Melo Alves \\ Secretária Nacional de Desenvolvimento Regional do Ministério da Integração Nacional \\ João Mendes da Rocha Neto \\ Coordenador Geral de Planos Regionais e Territoriais da Secretaria Nacional de Desenvolvimento Regional do \\ Ministério da Integração Nacional \\ Paulo Pitanga do Amparo \\ Coordenador Geral de Planejamento Estratégico da Secretaria de Desenvolvimento Regional do Ministério da \\ Integração Nacional
}

Recebido: 11/11/2014 Versão revisada (entregue): 23/12/2014 Aprovado: 17/02/2015

\section{Resumo}

Este artigo discute e avalia o percurso da Política Nacional de Desenvolvimento Regional (PNDR), de seu lançamento pelo Ministério da Integração Nacional, em 2003, aos dias atuais. Uma primeira seção examina em retrospectiva os desafios impostos a uma política regional de âmbito nacional no país, em que as desigualdades socioeconômicas entre regiões, por quaisquer indicadores, se mostram ainda marcantes; revê a trajetória da PNDR; apresenta seus fundamentos e instrumentos propostos; e analisa as dificuldades enfrentadas no processo de sua implantação. Uma segunda seção revê o processo conferencial instaurado em 2012 - $1^{\text {a }}$ Conferência Nacional de Desenvolvimento Regional -, por meio do qual o Ministério da Integração Nacional promoveu um amplo debate social e federativo com vistas a colher subsídios para a elaboração de uma proposta legitimada que permitisse seu envio à apreciação do Congresso Nacional. Uma terceira seção destaca os principais aspectos da proposição resultante do processo conferencial da PNDR; a quarta e última seção informa sobre o andamento dos procedimentos adotados com vistas à transformação da PNDR em Política de Estado.

Palavras-chave | Brasil; desigualdades; PNDR; Política Nacional de Desenvolvimento Regional; política regional.

Código JEL | P25; R11; R58. 


\title{
BRAZILIAN REGIONAL POLICY: RETROSPECTIVE ANALYSIS AND NEW DIRECTIONS
}

\begin{abstract}
This paper discusses and evaluates the path covered by the National Policy on Regional Development (NPRD) of Brazil, from its launching by the Ministry of National Integration in 2003 until nowadays. The first section examines through a retrospective standpoint the political and institutional challenges imposed to a national regional policy aimed at tackling socioeconomic disparities in a country where these are still severe by any standards. It also briefly retraces the path covered by NPRD since its launching in 2003 up to the present date; examines its foundations and proposed instruments; and analyses some hurdles faced up along its implementation. A second section reexamines the proceedings of the 1 st National Conference on Regional Development, which the Ministry of National Integration set out in 2012 with a view to launch a nationwide debate aimed at gathering feed-back for the elaboration of a politically and socially legitimized NPRD proposal to be submitted to the Brazilian National Congress. A third section puts forth the main traits of NPRD's formal proposal as resulting from the 1st National Conference on Regional Development; and the fourth and last section dwells on the progress achieved so far by the Ministry of National Integration for securing the approval of the law which shall turn NPRD into a State policy.
\end{abstract}

Keywords | Brazil; inequalities; National Policy on Regional Development; NPRD; regional policy.

JEL-Code | P25; R11; R58.

\section{POLÍTICA REGIONAL BRASILEÑA: ANÁLISIS RETROSPECTIVO Y NUEVAS RUMBOS}

\section{Resumen}

En este artículo se analiza y evalúa la ruta seguida por la Política Nacional de Desarrollo Regional (PNDR), su lanzamiento por el Ministerio de Integración Nacional en 2003 hasta nuestros días. En la primera sección se analiza en retrospectiva los desafíos planteados a la política regional a nivel nacional en el país, en el que las desigualdades socioeconómicas entre regiones, en función de cualquier indicador, se muestran aún significativas; se aborda la historia de la PNDR; se presentan sus fundamentos e instrumentos propuestos; y se analizan las dificultades que enfrentan en el proceso de su implementación. En la segunda sección se revisan los procedimientos de 2012 respecto a la $1^{\text {a }}$ Conferencia Nacional de Desarrollo Regional, a través del cual el Ministerio de la Integración Nacional promovió un amplio debate social y federativo, para obtener subsidios para el desarrollo de una propuesta legítima, que le permitiera su presentación al Congreso Nacional. En la tercera sección se destacan los principales aspectos de la propuesta resultante de la Conferencia; la cuarta y última sección informa sobre el progreso de los procedimientos adoptados con el fin de transformar la PNDR en política de Estado.

Palabras-clave | Brasil; desigualdades; PNDR; Política Nacional de Desarrollo Regional; política regional.

Código JEL | P25; R11; R58. 


\section{Introdução: a PNDR em retrospectiva}

O lançamento da Política Nacional de Desenvolvimento Regional (PNDR), em fins de 2003, tem um significado histórico no que tange ao tratamento da questão regional no Brasil. Até então, a instituição de políticas e instrumentos de governo voltados para a diminuição das desigualdades socioeconômicas entre regiões havia tido por objetivo ou responder às pressões decorrentes de crises pontuais, muitas vezes setoriais - como aquelas decorrentes das graves secas que assolaram $\mathrm{O}$ Nordeste, em fins do século XIX e primeiras décadas do século passado -, ou incorporar porções do território ao processo de desenvolvimento nacional - como o foi a Marcha para o Oeste, durante o Estado Novo, iniciada ao final da primeira metade do século passado -, ou ainda estabelecer uma base de consenso junto às elites regionais, mediante o qual se aprofundasse o processo de industrialização baseado na substituição de importações, originalmente sediado em São Paulo, que redundou na instauração, entre 1956 e 1975, de um amplo conjunto de instrumentos institucionais e econômico-financeiros de atuação específica para as regiões Norte e Nordeste do país.

Os reflexos das iniciativas e investimentos realizados naquele período em regiões menos desenvolvidas foram, sem dúvida, essenciais na promoção da desconcentração industrial, que se acentua a partir dos anos 1970. Enquanto em 1968, por exemplo, o Sudeste respondia por $81,3 \%$ do Valor da Transformação Industrial (VTI), essa participação, entre 1973 e 1984, reduz-se de 77,9\% para $70,9 \%$, com queda significativa, sobretudo, da participação de São Paulo, que passa de 57,9\% para 49,6\%, no mesmo período. As demais regiões, por sua vez, registram aumento de participação relativa, com destaque para o Nordeste, que passa de 5,9\% para 10,3\% de participação naquele agregado. Na década de 1980, e até meados da década de 1990, em face da crise fiscal e financeira do Estado brasileiro, verifica-se um abandono das políticas até então ensaiadas, e a consequente reversão do processo de desconcentração.

É necessário frisar, contudo, que drásticas disparidades regionais permanecem. A Figura 1, a seguir, ilustra essa persistência, vista pelo ângulo da capacidade produtiva das regiões. Note-se que, tomando-se como referência os anos 1939 e 2003, as rendas per capita das regiões Norte e Nordeste permanecem praticamente as mesmas, algo em torno de $70 \%$ e $50 \%$ da média nacional, respectivamente. Observe-se, por outro lado, ao longo daquele período, a tendência à convergência do mesmo indicador para as regiões Sul e Sudeste, bem como uma vigorosa expansão da capacidade produtiva da região Centro-Oeste, lastreada, sobretudo, no agronegócio, cuja renda per capita tende claramente a se aproximar da apresentada pelas duas regiões mais dinâmicas do país. 
Figura 1 Renda per capita relativa (Brasil=100) entre os anos 1939 e 2003

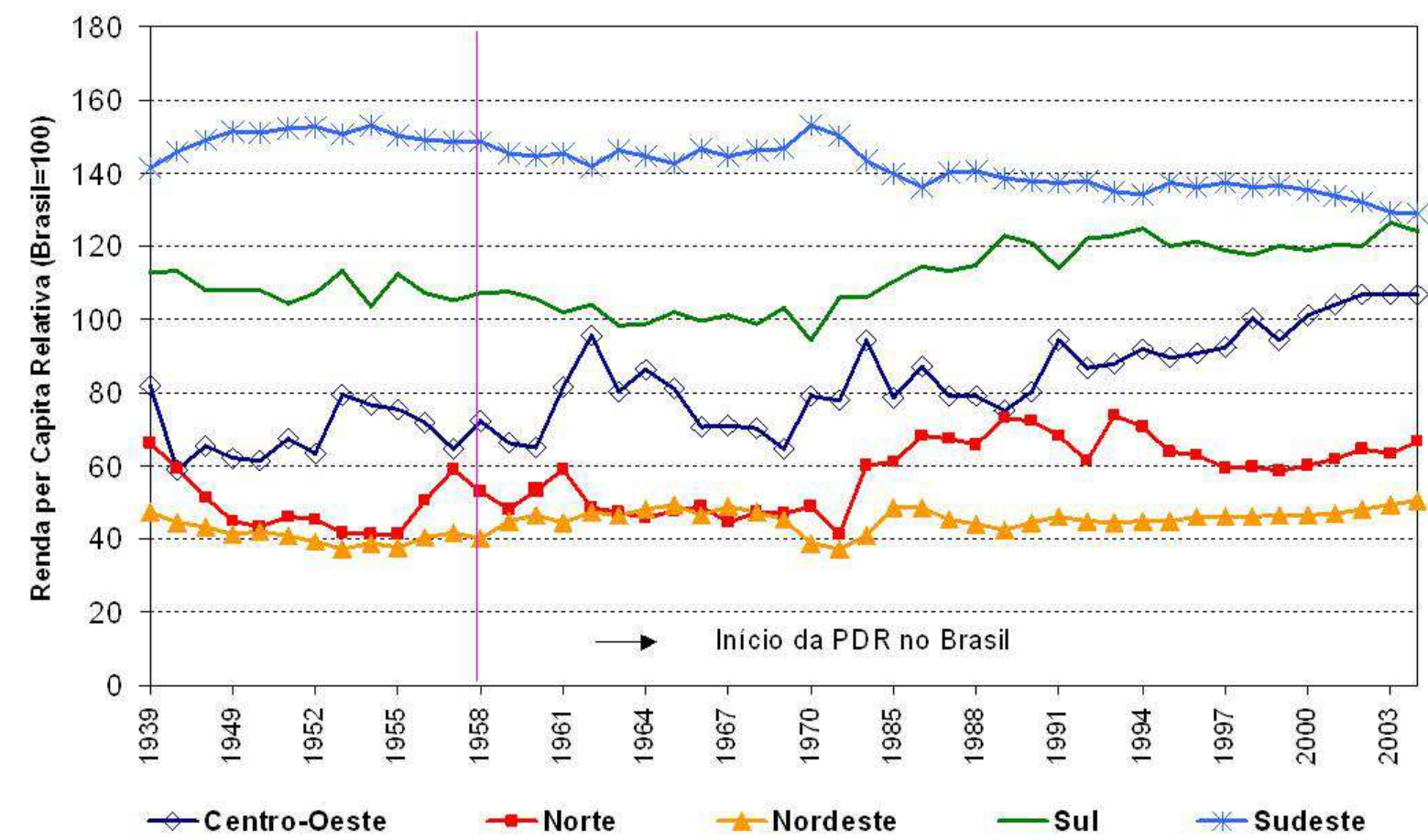

Fonte: Texto de Referência da I CNDR (2012).

As acentuadas disparidades regionais não passaram ao largo da Constituição Federal de 1988, que elucidou em diversos dispositivos a questão, notadamente quando estabelece ser objetivo fundamental da República Federativa do Brasil reduzir as desigualdades regionais, destinando-se, nesse sentido, 3\% da arrecadação total do Imposto de Renda e do Imposto sobre Produtos Industrializados para o setor produtivo das regiões Norte, Nordeste e CentroOeste - previsão que deu origem aos Fundos Constitucionais de Financiamento do Norte, Nordeste e Centro-Oeste (FNO, FNE e FCO).

A partir de 1996, ocorre um processo paulatino de retomada da importância do planejamento e das políticas de base territorial e regional. Em uma primeira etapa, a política regional é baseada em "eixos de desenvolvimento" e assume uma visão de competitividade a partir de "territórios vencedores" visando a uma maior integração internacional, favorecendo-se, no entanto, a "fragmentação interna". Com efeito, esse período, marcado pela priorização de "eixos dinâmicos" com foco no mercado internacional, embora, como se haja apontado, trouxesse riscos de romper os laços de solidariedade entre territórios competitivos e não competitivos, assegurou a retomada do debate em torno da espacialidade do desenvolvimento brasileiro. Ainda, é importante salientar a criação do Ministério da Integração Nacional, em 1999, com o mandato de conduzir a política regional brasileira. 
As intervenções do período ganharam uma conotação setorial, dificultando o planejamento integrado do território, já que estavam ancoradas na ideologia da competitividade espacial. A política regional esteve subordinada à tendência mundial e, como aponta Sunkel (1999), as atividades marcantes do período de globalização se caracterizariam pela "[...] amplitude territorial e incorporação de novos espaços à economia de mercado [...].” (SUNKEL, 1999, p. 183). Assim, a reconcentração e acentuação das desigualdades tornaram-se crescentes no Brasil da década de 1990, e na maior parte das nações do mundo no período, variando de magnitude de acordo com os processos de formação social e econômica desses países.

Em relação à competitividade espacial, vê-se que o novo ciclo de expansão do capital sob o comando das grandes corporações não se dá de forma homogênea: ele é seletivo em espaços e setores produtivos. As "escolhas" do capital cada vez mais passam a considerar sua capacidade (e possibilidade) de reprodução. Essa seletividade resulta em uma hierarquização entre espaços subordinadores e subordinados, que não é nova no sistema; o que a diferencia, atualmente, são os níveis e formas de uso do território, mediados pela técnica. A hierarquia na rede, também, não é garantida ou estável, ela está sujeita à concorrência acirrada entre os espaços, "mediada" pelo mercado, que, segundo Offe (1999), confere primazia à "[...] eficiência, contanto que as vantagens competitivas venham com um prêmio por melhores métodos de produção e melhores produtos [...].” (OFFE, 1999, p. 135).

Santos (1991) reforça o entendimento ao dizer que, quanto mais os lugares se mundializam, mais se tornam singulares e específicos, isto é, "únicos", na medida em que os elementos do espaço são submetidos a uma especialização desenfreada e afirma: "O território a cada momento foi organizando-se de maneira diversa, muitas reorganizações do espaço se deram e continuam acontecendo, atendendo aos reclamos da produção da qual é arcabouço." (SANTOS, 1991, p. 45). Do processo consta ainda, entre outras, questões relacionadas com ordenamentos e (re)ordenamentos espaciais tendo como base o desenvolvimento das políticas públicas, sobretudo as de infraestrutura e aquelas ligadas às questões econômicas.

A estratégia de "privilegiar" espaços se fez presente de uma forma intensa em alguns setores produtivos, que ao usarem o espaço como mercadoria utiliza também seu conjunto de atributos (naturais e artificiais) para realizar-se e reproduzir-se. No caso brasileiro, tal opinião é corroborada por Araújo (2000) ao comentar que: "[...] a inserção do Brasil na economia mundial globalizada tende a ser amplamente diferenciada, segundo os diversos subespaços econômicos desse heterogêneo país [...]." (ARAUJO, 2000, p. 86). Essas diferenças espaciais decorrem das "escolhas" já mencionadas e de intervenções do Estado brasileiro, que acabam por desconsiderar, muitas vezes, a complexidade do espaço nacional, reforçando o cenário de agudas desigualdades inter e intrarregionais. 
No Brasil da década de 1990, as políticas especializadas e, consequentemente, os planos setoriais fizeram frente ao planejamento regional mais amplo e acentuaram a desarticulação da intervenção no território. Isso teve origem no próprio sistema de planejamento regional brasileiro, que manifestou baixa capacidade em mobilizar agentes em torno de suas diretrizes e institucionalidades. Existem marcas claras desse processo quando os tradicionais órgãos de planejamento e desenvolvimento regional, dentre os quais se destacavam a Superintendência de Desenvolvimento do Nordeste - SUDENE, a Superintendência de Desenvolvimento da Amazônia - SUDAM, a Superintendência de Desenvolvimento do Centro-Oeste - SUDECO e a Superintendência de Desenvolvimento do Sul - SUDESUL, entraram em colapso, sendo extintos em 2001.

A segunda fase deste processo, a partir de 2003, constitui um esforço voltado para a construção de um novo projeto nacional de desenvolvimento, que, no campo regional, culmina com a proposição da PNDR. A originalidade da concepção teórica dessa Política, e daí sua importância histórica frente às abordagens anteriormente adotadas, deu-se pela ruptura com a visão da questão regional como o resgate de uma dívida histórica que existiria entre macrorregiões "ricas" (Sudeste e Sul) e "pobres" (Norte, Nordeste e Centro-Oeste). Tratava-se agora de superar esta dicotomia, encarando-se a desigualdade regional como problema nacional, que deve, portanto, ser tratado no âmbito de um projeto nacional de desenvolvimento, mediante o qual o potencial e a diversidade das regiões sejam aproveitados e dinamizados, promovendo-se simultaneamente a integração nacional e uma gradual convergência de renda entre regiões.

Caberia à PNDR atuar em múltiplas escalas, pois desigualdades regionais não se manifestam apenas quando se comparam indicadores - demográficos, econômicos, educacionais, de saneamento, de ciência e tecnologia, entre outros entre regiões, mas também entre sub-regiões de uma dada macrorregião. Há graves desigualdades regionais, por exemplo, entre as microrregiões de Campinas e do Vale da Ribeira, no estado de São Paulo, como entre Alagoas e Pernambuco, no Nordeste.

A PNDR foi lançada pelo Ministério da Integração Nacional (MI) em 2003 e institucionalizada, como política de governo, por intermédio do Decreto $\mathrm{n}^{\circ}$ 6.047, de 22 de fevereiro de 2007, com o objetivo de reduzir as desigualdades de nível de vida entre as regiões brasileiras e promover a equidade no acesso a oportunidades de desenvolvimento.

O Decreto 6.047, em seu Anexo II, definiu uma tipologia para a PNDR, com o objetivo de orientar a interação desta com políticas setoriais, bem como balizar a ação de planos, programas e projetos sob a governabilidade do MI. A abordagem em "múltiplas escalas geográficas" da PNDR se daria mediante a elaboração de Planos Estratégicos de Desenvolvimento com prioridade para as regiões Norte, 
Nordeste e Centro-Oeste, cuja elaboração e implementação seriam coordenadas pelas instituições responsáveis pelo desenvolvimento das respectivas áreas de abrangência - atualmente SUDAM, SUDENE e SUDECO - vinculadas ao MI.

$\mathrm{Na}$ escala sub-regional, a atuação de daria por meio dos programas do governo federal, considerada a escala mesorregional, e em "regiões prioritárias" indicadas no Anexo I do Decreto $\mathrm{n}^{\circ}$ 6.047. Também foram elencadas como áreas de tratamento prioritário da PNDR o Semiárido, a Faixa de Fronteira e as Regiões Integradas de Desenvolvimento (RIDE), bem como áreas consideradas relevantes pelo ângulo do impacto territorial presumido decorrente de investimentos estruturantes promovidos pelo Governo Federal.

De modo a assegurar condições de governança, a PNDR previu, no nível federal, a Câmara de Políticas de Integração Nacional e Desenvolvimento Regional, composta por diversos ministérios, que favorecesse a ação conjunta do governo federal em áreas prioritárias, conforme critérios definidos na Política; no nível macrorregional, apontam-se os Conselhos Deliberativos da SUDAM, SUDENE E SUDECO $^{1}$; e no nível sub-regional, ganham status os Fóruns das Mesorregiões Diferenciadas e demais instâncias sub-regionais de representação políticoinstitucional como espaços de permanente diálogo e negociação entre o governo federal, governos estaduais, prefeituras, sociedade civil e setor empresarial, com responsabilidades no planejamento, monitoramento e avaliação das ações voltadas ao desenvolvimento.

No tocante ao financiamento, a PNDR contaria com as fontes usuais existentes (OGU, Fundos Constitucionais de Financiamento, Fundos de Desenvolvimento do Nordeste, recursos dos agentes financeiros oficiais, e incentivos e benefícios fiscais), acrescidos dos recursos do Fundo Nacional de Desenvolvimento Regional (FNDR), conforme entrevisto na Proposta de Emenda à Constituição (PEC) da Reforma Tributária apresentada em 2008. Os recursos do FNDR proviriam da vinculação no texto constitucional de $4,8 \%$ das receitas de tributos federais, cuja base cresceria com a transformação das contribuições sociais sobre mercadorias e serviços (PIS/COFINS) em um Imposto sobre Valor Agregado (IVA) federal. A previsão era a destinação de $60 \%$ dos recursos do fundo ao financiamento do setor produtivo e $40 \%$ a investimentos estruturantes.

Em retrospectiva, é possível, sem dúvida, afirmar que a PNDR lançou novas bases para o enfrentamento da questão regional no país, notadamente porque:

\footnotetext{
${ }^{1}$ Vale lembrar que os planos diretores para o desenvolvimento do Nordeste, elaborados na região, eram aprovados no Conselho Deliberativo da SUDENE por governadores eleitos e enviados ao Congresso Nacional para apreciação e aprovação. A partir da segunda metade dos anos 60, passam a constituir meros capítulos dos planos nacionais.
} 
i) Ultrapassou a visão tradicional que limitava o problema regional brasileiro à dimensão macrorregional, ao propor uma abordagem nacional articulada em múltiplas escalas;

ii) Estabeleceu uma tipologia baseada em dois indicadores econômicos (taxa de variação geométrica do PIB per Capita e rendimento domiciliar monetário mensal per capita, por microrregião), que permitiu uma visão sintética das desigualdades inter e intrarregionais - do país, lançando parâmetros de orientação territorial para políticas e investimentos, a exemplo dos critérios de aplicação dos Fundos Constitucionais de Financiamento;

iii) Deu ênfase à diversidade regional do país como ativo a ser explorado;

iv) Identificou a necessidade de coordenação intersetorial no âmbito federal, como meio de assegurar a convergência das demais políticas federais aos objetivos da PNDR.

A implementação da PNDR, no entanto, sofreu sérios reveses, decorrentes seja dos pressupostos que a embasaram, seja da evolução do contexto político, institucional e econômico do país.

Quanto à elegibilidade de territórios, embora a tipologia proposta para a PNDR tenha contribuído para a criação de parâmetros objetivos para eleição de territórios prioritários de atuação, ela não atingiu seu objetivo por três razões essenciais:

1 - Em 2003, ainda em sua fase de formulação, a proposta da PNDR, inclusive a tipologia, não foi discutida nem legitimada, de forma participativa, no âmbito federativo, descolando-se, muitas vezes, das expectativas de lideranças territoriais e das regionalizações adotadas pelos Estados.

2 - A priorização de territórios, especialmente nos próprios programas do MI, aconteceu por meio das clássicas regiões-foco - semiárido, mesorregiões diferenciadas e faixa de fronteira - não se tendo levado em consideração a tipologia estabelecida.

3 - A tipologia não foi assumida pelo governo federal como parâmetro para a territorialização das políticas setoriais.

No tocante à temática da setorialização x territorialização, é importante destacar a contribuição de Mueller (1982, p. 166), ao distinguir formas de ação do Estado, por meio de suas políticas públicas:

Em linhas gerais, a intervenção pública se organiza em torno de duas lógicas - a lógica territorial e a lógica setorial - cada uma com uma racionalidade própria. Através da lógica territorial o sistema social a ser regulado pela ação do Estado é uma circunscrição espacial (seja uma unidade político administrativa como um município, estado ou região), uma zona com status particular (como a floresta) ou também um 
componente territorial de uma política global (como a de descentralização). Através da lógica setorial, o Estado procura regular a reprodução de uma entidade mais abstrata constituída por um domínio de atividade delimitado verticalmente (como indústria, saúde, agricultura).

Cabe destacar ainda:

Essas duas lógicas de intervenção seriam diferentes, porque remetem a duas dialéticas sociais diversas. No primeiro caso [territorial], diz respeito à relação entre centro e periferia e está no cerne da intervenção estatal. No segundo, refere-se a dialética global-setorial [...] (MUELLER, 1982, p. 166).

Apesar de distintas, as duas lógicas se tocam, uma vez que "[...] na prática, toda política pública concretiza-se no território.” (STEINBERGER, 2013, p. 63). Recortes espaciais prioritários em políticas especializadas geram regionalizações que, ora se superpõem, ora são disjuntas e muitas vezes contraditórias. A excessiva regionalização pode induzir o formulador a uma visão atomizada do território, que passa a ser recortado e instrumentalizado a partir de uma lógica particular onde incidem certos dispositivos legais e, portanto, ações específicas. Pode preponderar inclusive um viés imobilista, que não passa a reconhecer a sua dinâmica.

No que tange à estrutura de governança da PNDR, algumas questões merecem destaque. A Câmara de Políticas de Integração Nacional e Desenvolvimento Regional, criada em 2003, foi instalada em junho de 2004 e descontinuada em 2007, de modo a que a PNDR perdeu uma de suas grandes institucionalidades para a governança e coordenação federal da Política. Em 2012, a Câmara foi reinstalada, embora ainda necessite de regularidade e pauta definida de trabalho.

No nível macrorregional, embora tenha havido a recriação da SUDAM e SUDENE em 2007, bem como a criação da SUDECO em 2009, reconhece-se que as Superintendências ainda carecem de estrutura para funcionamento e atendimento de suas competências. As palavras de Araújo denotam a pouca capacidade de as Superintendências decidirem efetivamente: "Os conselhos deliberativos das superintendências, isto é, seus fóruns políticos, atualmente são uma imagem desbotada do que foram nos anos 60." (ARAÚJO, 2000). As funções de decisão política e, consequentemente, de instância garantidora dos recursos necessários à viabilização da PNDR no âmbito desses conselhos passaram a ser fragilizadas. No nível sub-regional, os Fóruns das Mesorregiões Diferenciadas, que seriam instâncias de coordenação de ações no território, não conseguiram o apoio necessário para seu funcionamento, especialmente após a descontinuidade do Programa destinado às Mesorregiões com o novo Plano Plurianual 2012-2015. 
No âmbito federativo, a PNDR encontrou dificuldades de identificar e estabelecer bases de cooperação com instâncias de governança nos níveis sub-regionais que assumissem a interlocução no território com vistas à implementação de ações de interesse do desenvolvimento regional, e no âmbito setorial não aconteceu a coordenação entre a PNDR e outras instâncias de governança, a exemplo dos Comitês de Bacia e dos Territórios da Cidadania.

A questão do financiamento, no entanto, pode ser vista como o fator explicativo de peso para as dificuldades de implementação enfrentadas pela PNDR nos últimos dez anos, pois a não aprovação do FNDR, no âmbito da PEC da Reforma Tributária, obrigou seus gestores a contar apenas com os antigos instrumentos para o financiamento do desenvolvimento regional, largamente insuficientes para o desafio da política, tendo, inclusive, sofrido forte contingenciamento nos últimos anos, como pode ser observado no gráfico a seguir (Figura 2).

Figura 2 Índice de evolução dos gastos dos programas da PNDR, inscritos nos PPA 2004-2007 e 2008-2011, no período 2004-2010

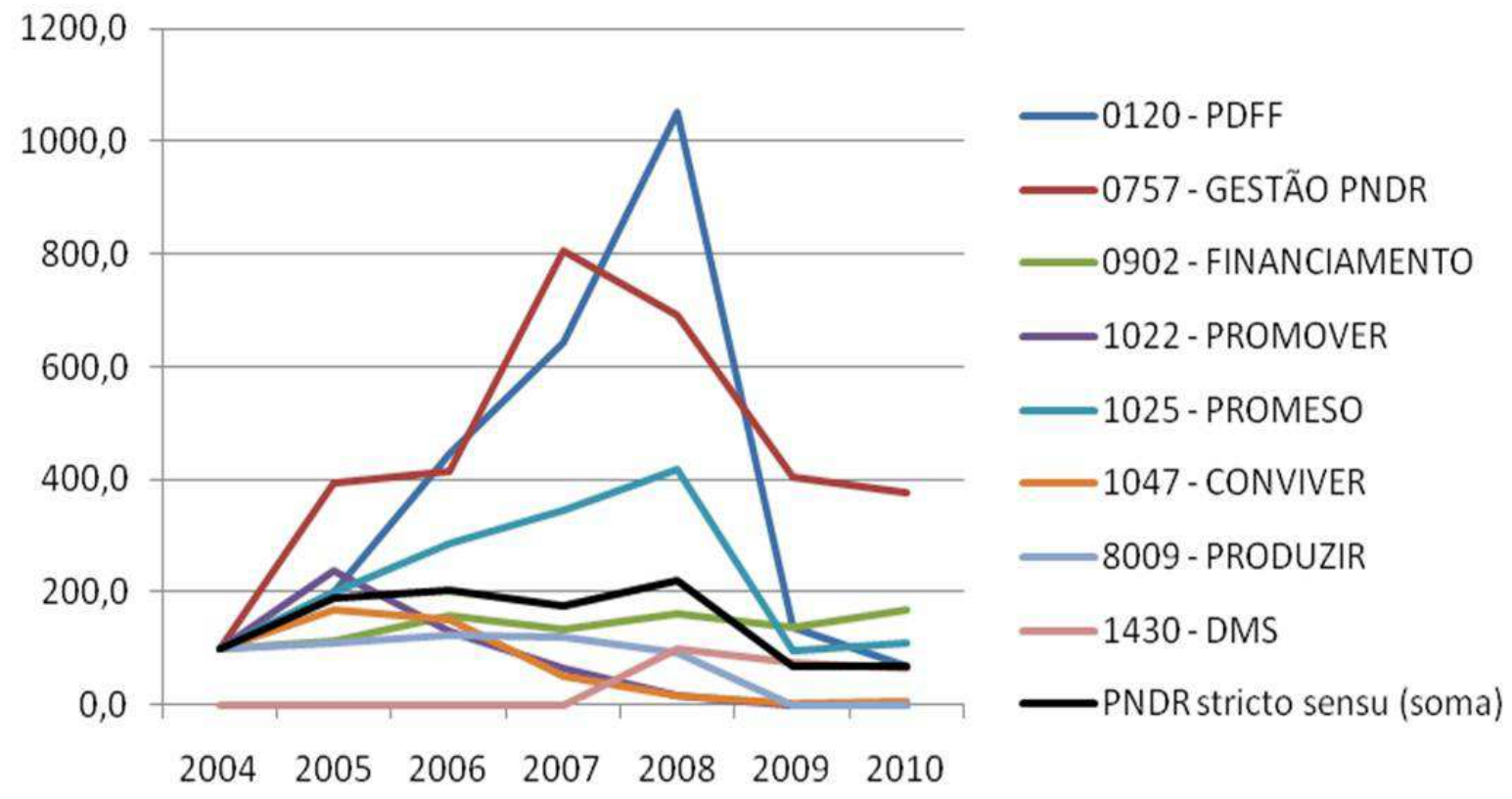

Fonte: Texto de Referência da I CNDR (2012).

Já os incentivos e benefícios fiscais, os Fundos Constitucionais de Financiamento (FNO, FNE e FCO) e os Fundos de Desenvolvimento (FDA, FDE e, mais recentemente, o FDCO), embora apresentem expressiva renúncia fiscal e fonte de recursos para o desenvolvimento regional, atendem tão somente ao setor produtivo privado, e são regulamentados por legislações que adotam abordagens e recortes territoriais que não convergem necessariamente com os objetivos e territórios prioritários da PNDR. 


\section{Da Fase I à Fase II da PNDR: a Conferência Nacional de Desenvolvimento Regional}

Conforme exposto anteriormente, em 2011, após quase uma década do lançamento da PNDR, não havia dúvida que se mostrava necessário reformular a PNDR, de modo a adequá-la às condições político-institucionais, às novas dinâmicas regionais e ao atual estágio de desenvolvimento da economia brasileira, evidentemente que incorporando os indubitáveis avanços e aprendizados resultantes da etapa anterior.

Nesse sentido, a nova equipe dirigente que assume o MI em 2011 se posiciona oficialmente a favor de relançar a PNDR. Foram retomadas negociações junto à Casa Civil e ao Ministério do Planejamento com vistas à convocação da Câmara de Políticas de Integração Nacional e Desenvolvimento Regional, e uma nova proposta de Política (PNDR II) passou a ser gestada no âmbito da nova Secretaria de Desenvolvimento Regional (SDR).

Para a proposição da PNDR II, o MI adotou a pertinente decisão de convocar um amplo debate social e federativo com o objetivo de colher subsídios para a elaboração de uma proposta pela qual a PNDR fosse transformada em política de Estado, condição entendida como necessária ao grande desafio de propiciar um maior equilíbrio regional ao país. Para esse fim, foi instituída, em 2012, a $1^{\text {a }}$ Conferência Nacional de Desenvolvimento Regional (CNDR).

Cabe mencionar que ao propor a realização de uma ampla Conferência Nacional, por meio da qual resultassem princípios e diretrizes em apoio à formulação da PNDR II, o MI alinhou-se à abordagem adotada pelo governo federal para fins de agregar participação social à formulação de políticas públicas, como tinham sido os casos das Conferências Nacionais de Saúde, Cidades, Segurança Pública, entre outras.

A CNDR foi, sem dúvida, um grande esforço político, organizacional e financeiro empreendido pelo MI, por sua Secretaria de Desenvolvimento Regional (SDR), com vistas a legitimar a PNDR II por intermédio da concertação federativa e social. Foi elaborado um documento de referência em orientação às discussões e deliberações que teriam lugar ao longo do processo conferencial.

Com base naquele documento, um amplo debate de âmbito nacional foi instaurado, com a realização de 27 etapas estaduais e 5 etapas macrorregionais, que reuniram cerca de 13.000 participantes de sociedade civil, empresariado, setor público e instituições de ensino superior, pesquisa e extensão. A plenária nacional, ocorrida em março de 2013, em Brasília, teve a participação de 354 delegados e cerca de 2.400 participantes, tendo sido aprovados 21 Princípios e 95 Diretrizes (BRASIL, 2013). 
O processo de construção da conferência teve início no primeiro trimestre de 2012, com a constituição da Coordenação Executiva da I CNDR, sendo posteriormente instituído o Comitê Ministerial e a Comissão Organizadora Nacional. A CNDR adotou como tema "Desenvolvimento Regional para a Integração Nacional” e estabeleceu como objetivos específicos:

- Formular princípios e diretrizes para uma nova política regional brasileira;

- Constituir um espaço de deliberação, divulgação, difusão e diálogo federativo e social acerca de temas e políticas de Desenvolvimento Regional;

- Contribuir para a elevação da PNDR à condição de política de Estado;

- Apontar caminhos para a interação entre as políticas de desenvolvimento regional e as demais políticas públicas;

- Promover o fortalecimento da cooperação e uma maior aproximação com os demais entes federados, academia e sociedade em geral;

- Lançar as bases para a constituição de mecanismos de governança regional nos Estados (BRASIL, 2013).

Participaram da realização do evento, como parceiros da SDR/MI, o IPEA e o MDIC. Periodicamente o IPEA já realizava a Conferência do Desenvolvimento (Code). Pela convergência dos temas, optou-se por realizar a Code e a CNDR em paralelo, de forma a compartilhar infraestrutura e logística e de aumentar o leque de atividades disponíveis para os participantes. O MDIC, por sua vez, participou de todas as etapas estaduais com a Agência Brasileira de Desenvolvimento Industrial - ABDI. Foram realizados eventos paralelos em cada Estado e uma agenda específica voltada para constituição da Agenda de Desenvolvimento Produtivo de cada Estado. Ao MI, coube viabilizar com os governos estaduais a coordenação e a organização do processo da I CNDR nos respectivos estados; atuar para a formação das Comissões Organizadoras Estaduais - COEs; atuar para a adequada incorporação de todos os segmentos envolvidos no processo conferencial nos estados; mobilizar os segmentos; assessorar e acompanhar as COEs; divulgar a CNDR nos estados e apresentar o texto de referência para a conferência.

O texto de referência produzido pelo MI, anteriormente mencionado, foi o ponto de partida para a discussão em todas as etapas da I CNDR, e teve por objetivo apresentar os princípios, diretrizes e prioridades da política de desenvolvimento regional. O texto foi pautado por quatro eixos temáticos considerados centrais para a discussão do desenvolvimento regional no Brasil:

Eixo 1: Governança, Participação Social e Diálogo Federativo.

Eixo 2: Financiamento do Desenvolvimento Regional.

Eixo 3: Desigualdades Regionais e Critérios de Elegibilidade. 
Eixo 4: Vetores do Desenvolvimento Regional Sustentável.

O Eixo 4 foi subdividido nas seguintes vertentes: Estrutura Produtiva; Educação, Ciência, Tecnologia e Inovação; Infraestrutura e Desenvolvimento Regional; e Rede de Cidades.

Participaram das etapas da I CNDR representantes da sociedade civil, do setor empresarial, do poder público e das instituições de ensino, pesquisa e extensão. $\mathrm{Na}$ etapa nacional, além dos eleitos nas etapas estaduais, tiveram assento os delegados natos do governo federal, de conselhos nacionais de políticas públicas setoriais e coordenadores das Comissões Organizadoras Estaduais. Somados, esses representantes totalizaram 429 participantes.

A eleição de delegados nas etapas estaduais obedeceu ao quantitativo populacional de cada Estado, de forma a manter a representatividade da população entre os participantes do processo conferencial.

Para alcançar o objetivo de formular princípios e diretrizes para uma nova política regional brasileira, a CNDR optou por uma metodologia de natureza qualitativa, adotada ao longo de todo o processo conferencial. Dessa forma, os participantes inicialmente se reuniam em grupos de trabalho para construir propostas. Cada GT era relacionado a um Eixo Temático, buscando-se assim fomentar uma discussão mais qualificada a respeito de cada tema, tendo como roteiro o conteúdo do texto de referência apresentado. Ao final deste processo de debates em cada GT, os participantes elegiam as propostas a serem levadas para a priorização final, quando então os participantes de todos os grupos se reuniram diante do conjunto de todas as propostas originadas nos grupos para indicação daquelas de sua preferência. Cada participante recebeu adesivos diferenciados para escolher princípios e diretrizes de sua preferência. Após a contagem do número de adesivos fixado em cada proposta, as mais priorizadas foram encaminhadas como proposta de cada Estado para a Etapa Nacional da CNDR.

Nas etapas macrorregionais se repetiu esse procedimento, tendo como base as propostas recebidas dos estados. Cada conferência estadual e macrorregional priorizou 5 (cinco) princípios e 20 (vinte) diretrizes, que foram encaminhados para a Etapa Nacional. A Etapa Nacional manteve a metodologia qualitativa para elaboração e priorização final dos princípios e diretrizes.

A Carta Nacional resultante da I CNDR foi elaborada por Grupo de Trabalho (GT) específico montado na etapa nacional, composto por delegados e aprovada na Plenária Final. Sua elaboração contou com um painel de sugestões aberto a todos as pessoas que circularam pelo evento. O texto produzido pelo GT da Carta Nacional foi distribuído aos delegados no dia 22 de março de 2013, para que pudessem fazer propostas de emendas a serem submetidas ao conjunto dos delegados. As propostas de emendas apresentadas foram analisadas na Plenária Final. 


\section{Rumo à implantação da PNDR II como política de Estado}

Esta última seção do presente artigo discorre sobre os objetivos da proposta resultante do processo conferencial comentado na seção anterior, bem como do modelo de governança, e informa ao seu final sobre o andamento da PNDR II como Projeto de Lei para apreciação e votação pelo Congresso Nacional, com vistas à sua transformação em Política de Estado. Em grande medida o conteúdo apresentado a seguir é fiel ao Texto de Referência da Conferência Nacional de Desenvolvimento Regional, publicado pelo Ministério da Integração Nacional em 2012. A proposta de política resultante da I CNDR, em sua contextualização, explicita fatores econômicos, políticos e institucionais, prevalecentes nos contextos nacional e internacional, que considera norteadores de suas proposições.

De início, a PNDR II considera vencida e etapa do planejamento centralizado e das intervenções públicas de cima para baixo, que vigoraram nos anos 1970 e 1980, sinalizando assim para a necessidade da incorporação de processos que favoreçam o compartilhamento de decisões com atores mais próximos dos territórios: estados, municípios e sociedade civil, mas partindo de uma estratégia nacional, consonante com o que preconiza a chamada "terceira geração" de políticas regionais.

A PNDR II destaca o fenômeno da globalização e a emergência da economia do conhecimento ou "economia do aprendizado", segundo a qual a economia mundial vive um processo de transição para um paradigma de produção flexível de bens diferenciados, no qual a informação e o aprendizado passam a desempenhar um novo e estratégico papel, caracterizando o que se costuma chamar de economia do conhecimento, com impactos na questão regional, dandose ênfase à introdução de tecnologias aplicadas criativamente às condições e aos potenciais regionais, e eixos estruturantes fundamentais de qualquer esforço para acelerar o desenvolvimento das regiões mais atrasadas (BRASIL, 2012).

A nova proposta sublinha que, se a globalização e a economia do conhecimento tendem a integrar internacionalmente mercados e estruturas produtivas, o processo de inovação, por si só, é fortemente dependente de atributos e interações enraizadas no território, e com isso uma eventual tendência à homogeneização promovida pelo processo da globalização cairia por terra, visto que se ampliam assim "a importância das regiões e localidades" (BRASIL, 2012).

Destaca, contudo, a forte concentração espacial dos ativos intelectuais e da infraestrutura de pesquisa, desenvolvimento e inovação (P, D \& I) em territórios que dispõem de uma dotação prévia destes ativos, expandindo-se as possibilidades de geração de desigualdades entre países ou no interior de cada país (BRASIL, 2012). E chama a atenção para a tendência de declínio das regiões industriais tradicionais, por decorrência do deslocamento espacial da produção nos segmentos intensivos em recursos naturais, com o acirramento da concorrência 
entre territórios pela atração destes investimentos, e surgimento de novas aglomerações produtivas em países / regiões periféricas (BRASIL, 2012).

A proposta de PNDR II discute também a vertente desenvolvimento e sustentabilidade, argumentando que a sociedade está cada vez menos suscetível a aceitar modelos de crescimento com exploração indiscriminada de recursos naturais, com comprometimento do estoque de recursos naturais, em detrimento das gerações futuras, não havendo mais lugar, conseguintemente, para políticas de desenvolvimento sem que se considerem, simultaneamente, a sustentabilidade em suas várias dimensões (BRASIL, 2012).

Além disso, alerta para a expansão dos países emergentes e para o efeito China, com as economias emergentes crescendo a taxas superiores às dos países avançados, especialmente no quadro da crise estabelecida desde 2008, num quadro geopolítico crescentemente multipolar (BRASIL, 2012). A China, em especial, é vista como detendo um papel crucial. Com grandes escalas de produção, baixos salários, câmbio subvalorizado e crescentes investimentos em qualidade e P\&D, as exportações industriais da China têm implicado no esvaziamento e deslocamento em vários setores, cadeias produtivas, sistemas produtivos locais em economias locais e regionais em todo mundo. A dimensão de suas importações por outro lado, tem fortes impactos sobre os preços relativos das commodities.

No Texto de Referência (2012), três grandes consequências da expansão dos países emergentes e do efeito China são apontadas como geradoras de novos desafios e oportunidades para o desenvolvimento nacional e regional no Brasil e são aqui ressaltadas:

i) O rápido aumento da dependência brasileira ao mercado chinês de commodities, que se traduz em forte pressão no sentido de uma "especialização regressiva" da produção industrial brasileira, bem como um peso excessivo do setor primário na pauta de exportações do País;

ii) $\mathrm{O}$ crescimento presente e futuro da demanda por commodities como oportunidade para o Brasil, que possui condições excepcionais para atendê-la em função de sua disponibilidade de áreas agricultáveis, reservas minerais, capacidade empresarial e tecnologia, com possibilidades de expansão em regiões menos desenvolvidas, representando uma oportunidade de se avançar na redução das desigualdades espaciais.

iii) As mudanças no perfil e na composição da demanda industrial, mediante a incorporação de novas camadas sociais com poder aquisitivo médio, redundando em um redesenho regional do mapa de consumo, com criação de novos nichos para exportação de produtos industrializados de média tecnologia e consequente abertura de oportunidades para regiões menos desenvolvidas do país (BRASIL, 2012). 
A proposta da PNDR II analisa também com propriedade o impacto recente de políticas setoriais não explicitamente voltadas à redução das desigualdades regionais - as chamadas "políticas implícitas" de desenvolvimento regional - que redundaram em forte impacto na dinâmica das regiões, muita vez com repercussões quiçá mais expressivas do que as das próprias políticas voltadas explicitamente para tal fim.

Menciona, em primeiro lugar, a políticas de valorização real do salário mínimo, com seus desdobramentos nos benefícios previdenciários e na massa salarial dos funcionários públicos municipais, além dos avanços na previdência rural e nos benefícios assistenciais de prestação continuada (BPC), somados aos programas de transferência direta de renda, como o Programa Bolsa Família e seus diversos homônimos nos estados, que tiveram enorme impacto na renda das famílias (BRASIL, 2012). A expansão do crédito potencializou o aumento na renda e a geração de um círculo virtuoso, só interrompido recentemente em função da crise internacional.

Além das políticas sociais, a expansão dos gastos em infraestrutura, ao longo dos anos 2000, e de maneira mais intensa a partir de 2007, com o lançamento do PAC, têm alimentado o ciclo de crescimento com desconcentração regional, especialmente na fase de implantação dos projetos. De um lado, em razão de os investimentos em infraestrutura terem sido mais do que proporcionais à participação das regiões atrasadas no PIB. De outro, porque os empregos e a renda gerados pelos grandes investimentos de infraestrutura têm um impacto maior na dinamização destas regiões do que nas regiões mais desenvolvidas, que já possuem economias com grandes estoques de investimento e tecidos produtivos mais complexos (BRASIL, 2012).

Decisões estratégicas de localização de grandes investimentos no Nordeste, como as das futuras refinarias da Petrobrás - Premium I (MA), Premium II (CE), Abreu Lima (PE), Guamaré $(\mathrm{RN})$ - também teriam contribuído para alimentar o movimento desconcentrador assinalado. Destaca-se também a política de expansão do ensino superior e do ensino técnico e tecnológico para o interior, especialmente para a região Nordeste.

Conclui argumentando que embora as chamadas políticas implícitas tenham contribuído objetivamente para alimentar uma trajetória de desconcentração regional, mesmo que tímida, seu papel tem sido muito aquém de seu poder potencial de transformação, em razão da ausência de uma orientação estratégica clara e de mecanismos de coordenação capazes de assegurar coerência, sinergia e complementaridade dos vários esforços explícitos e implícitos de promoção do desenvolvimento regional. Este seria, naturalmente, o papel da nova PNDR (BRASIL, 2012).

Após o contexto acima esboçado, a proposta da PNDR II apresenta quatro objetivos principais com base nos quais são definidos critérios de elegibilidade em 
orientação à execução de ações e programas coordenados em espaços selecionados, que são:

\section{Convergência;}

2. Competitividade regional e geração de emprego e renda;

3. Agregação de Valor e Diversificação Econômica; e,

4. Construção de uma Rede Policêntrica de Cidades.

A consecução integrada desses objetivos é vista como necessária à consolidação da coesão socioeconômica, política e territorial do Brasil, à promoção da competitividade em regiões estagnadas economicamente, à diversificação econômica em regiões com produção concentrada e especializada, assim como à interiorização e harmonização do desenvolvimento do país.

A convergência é considerada objetivo maior da PNDR II, pois que se propõe a reduzir as diferenças no nível de desenvolvimento e na qualidade de vida entre e nas regiões brasileiras, mediante a promoção da equidade no acesso a oportunidades de desenvolvimento, fortalecendo-se a coesão econômica, social, política e territorial do país. Segundo o Texto de Referência (2012), o movimento de convergência necessário à consecução desse objetivo implica que:

- As economias dos espaços menos desenvolvidos cresçam sistematicamente acima da média nacional, de forma que o fosso que separa os indicadores de desenvolvimento - inter e intra regiões - seja reduzido. Isto pressupõe o reconhecimento da necessidade de tratamento diferenciado no que se refere à distribuição dos recursos federais e estaduais, baseado na solidariedade regional, um dos princípios fundamentais do federalismo cooperativo brasileiro;

- Se assegure equidade no acesso aos serviços, aos equipamentos públicos e ao conhecimento, de forma que as desigualdades de qualidade de vida e de oportunidades para as pessoas em razão de seu lugar de nascimento e/ou moradia sejam minimizadas, através da universalização do acesso aos serviços essenciais com qualidade, nomeadamente os de educação, saúde, energia, água, saneamento básico e informação;

- Se explicite o modelo de desenvolvimento desejado, que se espera seja participativo, inclusivo, inteligente e sustentável, voltado para as pessoas, que crie oportunidades para todos, reduzindo a pobreza e desconcentrando a renda, promovendo permanente transformação nas estruturas produtivas a partir da crescente incorporação de conhecimento e inovação, utilizando racionalmente os recursos disponíveis, de forma a otimizar seu uso no presente sem comprometer os direitos das gerações futuras;

- A coesão territorial seja reconhecida como parte essencial da coesão econômica, social e política da nação, não apenas no que tange à inclusão dos territórios e suas populações no acesso aos frutos do desenvolvimento, mas no reconhecimento das 
potencialidades e na valorização das capacidades produtiva e criativa de cada território, de seu patrimônio natural e cultural, da diversidade local e regional como riqueza e importante vantagem competitiva para o país (BRASIL, 2012).

O objetivo de competitividade regional e geração de emprego e renda remete à promoção da competitividade em espaços da região Sul que têm apresentado declínio populacional e elevadas taxas de emigração decorrentes de sua baixa capacidade de geração de oportunidades de emprego e renda e oferta de serviços, mas mira também para porções do Nordeste com histórico de exclusão e estrutura produtiva e oferta de serviços bastante precária.

No caso do Sul, nas ultimas décadas, diversos espaços, outrora dinâmicos, perderam dinamismo em razão de transformações tecnológicas e de reestruturação produtiva na agropecuária e na indústria, somando-se a estes espaços historicamente deprimidos, como a metade sul do Rio Grande do Sul. Este movimento se tem traduzido no esvaziamento populacional desses espaços em oposição a outros, que se adensam fortemente, agravando e gerando novas e importantes desigualdades intrarregionais.

Fazem-se necessárias, portanto, políticas de reconversão, diversificação e integração econômica, com foco em atividades inovadoras e portadoras de futuro, com grande potencial de incorporação de micro, pequenos e médios empreendimentos agrícolas, industriais e de serviços, no sentido de recuperar o dinamismo e a capacidade de retenção de população, contribuindo para o aumento da competitividade e para o desenvolvimento mais equilibrado da região (BRASIL, 2012).

Em alguns espaços do Nordeste, apesar da redução da histórica migração em direção ao Sudeste, em decorrência da desconcentração industrial e das políticas sociais nas últimas décadas, algumas microrregiões continuam registrando incipiente capacidade de retenção de sua população, especialmente na Bahia, Ceará, Maranhão, Rio Grande do Norte, e nos Vales do Jequitinhonha e Mucuri em Minas Gerais (BRASIL, 2012). Trata-se, em geral, de espaços com importante histórico de exclusão, com estrutura produtiva e de oferta de serviços bastante precárias. A ativação das economias locais a partir da exploração de seu potencial de forma inovadora e criativa, juntamente com a ampliação e melhoria na qualidade da oferta de serviços e uma melhor estruturação da rede de cidades, devem orientar a política nestes espaços (BRASIL, 2012).

O terceiro objetivo da PNDR II - agregação de valor e diversificação econômica - mira a agregação de valor e diversificação econômica em espaços com forte especialização na produção de commodities agrícolas e/ou minerais. Apesar de se tratar de espaços que, em geral, vem apresentando elevado dinamismo em decorrência da grande competitividade brasileira no segmento, e das condições favoráveis no mercado internacional para estes produtos, sua excessiva 
especialização tende a comprometer a sustentabilidade de seus processos de desenvolvimento.

Estariam contemplados nesse objetivo grandes espaços na região Centro-Oeste, e nas novas áreas de expansão da fronteira agrícola no Norte e no Nordeste, que têm hoje sua dinâmica fortemente associada à produção e exportação de commodities agrícolas. Segundo o Censo Agropecuário do IBGE (2010), cerca de $90 \%$ das exportações do Centro-Oeste corresponde a alimentos e produtos minerais com baixíssimo grau de processamento, sendo 66,3\% apenas dos complexos de soja e carnes. Diversas microrregiões na região Norte, no CentroOeste e no Norte de Minas, têm suas economias bastante dependentes de grandes empreendimentos minerais, em geral com limitado espraiamento de dinamismo no seu entorno.

Em geral, os produtos da pauta de exportação dessas regiões caracterizam-se pela baixa agregação de valor, e mercados dominados por oligopsônios, com preços sujeitos a fortes oscilações, baseados em modelos de produção socialmente pouco inclusivos e que, em geral, embutem elevados riscos e passivos ambientais (BRASIL, 2012).

O Texto de Referência (2012) aponta que o Brasil construiu nas últimas décadas uma importante capacidade competitiva no agronegócio, com investimentos em tecnologia e acúmulo de competência empreendedora, criando condições para assumir um papel estratégico de liderança na produção mundial de alimentos. Trata-se de uma base a partir da qual se pode avançar promovendo-se mudanças estruturais em direção a um modelo mais intensivo em conhecimento, ambientalmente sustentável e socialmente inclusivo, de um lado, avançando-se cada vez mais na diferenciação de produtos, na utilização de processos sustentáveis, na incorporação de conhecimento e, consequentemente, na agregação de valor; explorando-se localmente tanto as oportunidades que se abrem a montante das cadeias do agronegócio, como o de desenvolvimento da indústria de máquinas e equipamentos e toda uma gama de insumos tradicionais e inovadores no campo da biotecnologia, de TIC e outras, como a jusante, onde se abrem grandes oportunidades para empresas inovadoras de todos os portes focadas na diferenciação de produtos e serviços complementares (BRASIL, 2012). De outro lado, investindo na diversificação produtiva de forma a reduzir a vulnerabilidade das economias locais e induzir arranjos produtivos socialmente mais inclusivos, com forte participação da agricultura familiar e de micro, pequenas e médias empresas inovadoras industriais e de serviços (BRASIL, 2012).

Por fim, a construção de uma rede de cidades policêntrica como Objetivo 4 da PNDR II busca a consolidação de uma rede de cidades mais equilibrada, com maior harmonia entre os diferentes níveis hierárquicos, mediante a identificação e fortalecimento de polos, em diferentes escalas, operando como vértices ou elos de 
uma rede policêntrica em apoio à desconcentração e interiorização do desenvolvimento, promovendo-se uma organização territorial mais equilibrada.

A rede de cidades do Brasil atual é heterogênea, com aspectos de fragmentação e desarticulação nas porções norte, nordeste e centro-oeste e polarização no centrosul, o que torna a coesão territorial do País e o esforço de reduzir as desigualdades regionais um processo complexo, esforço verificado desde a década de $1950 \mathrm{com}$ a implantação das políticas desenvolvimentistas. Tal configuração foi construída a partir do final do século XIX e reflete os desequilíbrios dos processos de estruturação produtiva, industrialização, urbanização e mobilidade populacional, que promovem reflexos na escala intraurbana, contribuindo para a consolidação de cidades superpopulosas, de ampliada expansão periférica e incapazes de absorver grande contingente populacional.

O Texto de Referência (2012) traz ainda uma caracterização das macrorregiões brasileiras a partir de sua rede de cidades:

- $\mathrm{Na}$ região Sul-Sudeste emerge uma rede de cidades relativamente integrada, com peso crescente de cidades médias. Nas demais regiões observa-se uma dinâmica populacional e econômica bastante concentrada nas capitais. Contudo, verificam-se também importantes diferenças inter e intrarregional nestes espaços mais periféricos;

- No Nordeste, mais densamente povoado, evidencia-se uma concentração populacional nas capitais e em sua faixa litorânea, com uma população rural relativamente mais importante, sobretudo, em sua área semiárida. Bahia, Pernambuco e Ceará revelam maior interiorização de sua economia e população, com a presença de algumas cidades importantes. Nos demais estados é muito maior a concentração nas capitais, com baixíssima atividade no interior;

- Nas regiões de expansão da fronteira agrícola e mineral, no Centro-Oeste e no Norte, verifica-se a emergência de alguns centros urbanos médios no interior acompanhando as áreas mais dinâmicas. Na região Amazônica, as enormes distâncias, baixíssima ocupação e o isolamento imposto pelo bioma, dão origem a uma rede urbana muito específica, com alguns bolsões urbano-industriais, onde o principal elemento de organização do espaço é a oferta urbano-regional de serviços, especialmente de transporte (BRASIL, 2012).

Com base nesse contexto, a proposta da PNDR II remete a um grande estudo encomendado pelo Ministério do Planejamento (MPOG), publicado em 2008, intitulado Estudo da Dimensão Territorial para o Planejamento. Com base em uma estratégia de desconcentração e desenvolvimento mais equilibrado, o estudo encomendado pelo MPOG propõe "a construção de um Brasil Policêntrico", mediante a identificação dos principais macropolos e subpolos da rede urbana brasileira, além de eleger potenciais novos macropolos e subpolos que, se induzidos por políticas adequadas, poderiam vir a constituir, juntamente com os 
polos já consolidados, "vértices de uma rede policêntrica de cidades, estrutural para a nova organização territorial pretendida.” (BRASIL, 2012).

Uma rede de cidades policêntrica não atenderia apenas à dimensão urbana do desenvolvimento, mas também a dimensão rural, visto que se deve considerar o papel que os pequenos núcleos ou municípios rurais e as porções ruralizadas das cidades desempenham em suas relações com as cidades médias e com as metrópoles na rede, considerando que a dimensão do rural incorpora não apenas áreas dispersas, mas concentrações urbanas que se explicam por sua forte relação com os recursos naturais (CAMPOS; KRAHL, 2006, p. 87).

Além disso, segundo o Censo Demográfico do IBGE (2010), cerca de 70\% das cidades brasileiras possuem menos de 20 mil habitantes, e em parte importante delas o rural e urbano se confundem do ponto de vista econômico, cultural, social e ambiental, colocando-se a necessidade de se rever conceitos e estatísticas, abandonando-se uma visão dicotômica entre o rural e o urbano ${ }^{2}$. Uma rede de cidades mais equilibrada e melhor distribuída no território significa, também, mais acesso da população rural aos serviços e equipamentos públicos e mais oportunidades de renda, contribuindo para a melhoria de suas condições de vida e sua permanência no campo (BRASIL, 2012).

As conclusões do referido estudo são apontados na proposta da PNDR II como base para a definição dos atuais e novos polos a serem objeto de prioridade da Política, referendados a partir de uma ampla e ativa consulta a especialistas, policy makers e lideranças das próprias regiões. As políticas para alcançar o objetivo proposto devem estar voltadas para a indução e fortalecimento de novas centralidades, em consonância com as estratégias da política regional, a partir da provisão de infraestruturas de conexão, estruturação de sistemas produtivos e inovativos locais e regionais, bem como a garantia a serviços de qualidade ${ }^{3}$. Devem igualmente favorecer a integração e complementaridade intra e entre as diversas sub-redes, estimulando o trasbordamento do dinamismo para as suas áreas de influência.

Com vistas à consecução desses objetivos, a PNDR II, traz no seu bojo o Sistema de Governança para o Desenvolvimento Regional, que se estrutura a partir de elos fortes construídos horizontalmente, no âmbito do governo federal, bem como verticalmente com as superintendências de desenvolvimento, com os governos subnacionais e com a sociedade civil. O primeiro exercício dessa aproximação deu-se pelo próprio processo conferencial que construiu e legitimou a PNDR II, do qual tomaram parte mais de 13 mil pessoas em 33 conferências. Nesse sistema,

2 A OCDE, por exemplo, já utiliza os conceitos de cidades "predominantemente urbanas" e "predominantemente rurais" desde 1994 em suas estatísticas sobre urbanização.

3 O profundo impacto da construção de Brasília em termos da interiorização do desenvolvimento brasileiro é um exemplo extremo da efetividade deste tipo de política. 
um conjunto de mecanismos permite o diálogo entre as instituições do governo federal, através do Conselho Nacional de Desenvolvimento Regional, na dimensão estratégica e a Câmara de Integração Nacional e Desenvolvimento Regional, na dimensão tática. O sistema de governança também prevê a estruturação de conselhos nas escalas macrorregional e estadual e busca incorporar, em seu funcionamento, diversas instâncias sub-regionais que representam hoje, no Brasil, o esforço de organização e cooperação local voluntária, como são diversos fóruns, conselhos e colegiados territoriais hoje existentes no país.

A pactuação horizontal entre o Ministério da Integração Nacional e diversos órgãos do governo federal, bem como a vertical, junto a superintendências macrorregionais, estados e municípios, em torno de Pactos de Metas estratégicas e específicas, constituem o esforço de se avançar na transversalidade que a PNDR II exige em sua implementação. Tais compromissos mútuos dar-se-ão em torno de temas estratégicos, que compõem os chamados vetores do desenvolvimento, quais sejam: meio ambiente e sustentabilidade, dinamização produtiva, ciência e tecnologia, educação, saúde, transporte e logística, além de um tema que é transversal, a rede de cidades policêntrica.

Os pactos de metas específicas terão como objeto Regiões-Programa previamente definidas na proposta, como são a Faixa de Fronteira, o Semiárido e a RIDE do DF e Entorno, bem como outras a serem criadas por tempo determinado a partir da negociação no âmbito do sistema de governança da Política. Verifica-se que a proposta de PNDR II busca ser flexível ao acompanhar a dinâmica regional do país e atentar tanto para problemáticas regionais já existentes como para aquelas que venham a se manifestar em face da conjuntura, a exemplo das regiões que hoje recebem grandes obras estruturantes e que necessitam de ações diversas em função da alteração das dinâmicas territoriais advindas da implantação desses projetos. Há ainda um componente importante na PNDR II que se relaciona com a cooperação federativa, quando a política incorpora regiões que tenham sido deliberadas nas instâncias sub-regionais, rompendo com a orientação da PNDR I, que já elencava os espaços prioritários previamente.

Nesse sentido, instrumentos como os Pactos de Metas e o Fundo Nacional de Desenvolvimento Regional, cuja proposta de criação é retomada no âmbito da PNDR II, são estratégias para um gasto convergente nas regiões prioritárias e para a estruturação coordenada que possibilite a superação dos problemas que atingem diversas porções do território nacional.

\section{Considerações finais}

Apesar dos avanços recentes, o Brasil ainda apresenta desigualdades regionais graves, que se manifestam em diversas escalas, e intrarregionalmente. Os esforços 
empreendidos pelo poder central no sentido de formatar e implementar uma política regional que revertesse o atual quadro a partir dos anos 2000 não conseguiram ser suficientes para atingir tal objetivo. Dadas as fragilidades do processo de implementação da PNDR instituída em 2007, que se deu em um ambiente de excessiva setorialização do governo federal e desarticulação federativa, a Política foi reformulada a partir de amplo diálogo com a sociedade, com vistas à legitimação de seu conteúdo e futuro processo de implementação.

Após a elaboração do Projeto de Lei da PNDR II pelo Ministério da Integração Nacional a partir dos princípios e diretrizes priorizados que emanaram do processo conferencial, a proposta encontra-se em análise na Casa Civil da Presidência da República, que solicitou pareceres técnicos de diversos ministérios com os quais o tema dialoga diretamente. De lá, deverá seguir para o Congresso Nacional, onde deverá tramitar em 2015. Em meio a esse processo, tem-se buscado a construção de planos e pactos pelo desenvolvimento regional, o que tem requerido a definição de estratégias e processos de negociações continuadas e busca de consensos junto a diferentes agentes e atores sociais, bem como a necessidade de se articular e coordenar as políticas federais que têm nos territórios a base de sua atuação, considerando que o território no âmbito das políticas públicas não é mero receptáculo de ações do Estado, mas é ativo e está em permanente interação com a sociedade e com o próprio Estado (STEINBERGER, 2013, p. 62-63).

A implementação da PNDR II exigirá um esforço extra do Governo Federal e dos demais nos diversos níveis federativos no sentido de garantir a sua viabilização, que será alcançada com pleno êxito a partir da criação do ambiente propício ao diálogo entre órgãos setoriais, assim como dos mecanismos necessários que possam traduzir o resultado do diálogo em ações concretas. Nesse sentido, faz-se uso do conceito de transversalidade definido por Quim Brugué (2008), que parte da noção de uma necessária mudança de base na cultura organizativa de uma dada estrutura, para além de uma simples mudança no desenho institucional, com o propósito de se obter uma modificação da mentalidade organizativa, de modo que, do desenvolvimento de diálogos verticais entre estruturas e unidades hierárquicas, passe-se à construção de outras instâncias focadas nos diálogos horizontais, baseados em confiança mútua e propósitos convergentes e complementares. A transversalidade na PNDR II somente é passível de ser implementada a partir da maturidade das instituições e de agentes em torno da importância que tema desenvolvimento regional está a exigir.

\section{Referências}

ARAÚJO, Tânia Bacelar de. Dinâmica regional brasileira nos anos noventa: rumo a desintegração competitiva? In: Redescobrindo o Brasil: 500 anos depois. 
CASTRO, Iná Elias; MIRANDA, Mariana; EGLER, Cláudio. 2 ed. Rio de Janeiro: Bertrand Brasil, 2000.

BRASIL. Decreto $\mathbf{n}^{\circ} \mathbf{6 . 0 4 7}$, de 22 de fevereiro de 2007. Institui a Política Nacional de Desenvolvimento Regional. Diário Oficial, Brasília, fev. 2007.

- Instituto Brasileiro de Geografia e Estatística (IBGE). Censo demográfico 2010. Disponível em: <http://www.ibge.gov.br>. Acesso em: 1 nov. 2013.

- Instituto Brasileiro de Geografia e Estatística (IBGE). Regiões de influência das cidades. Rio de Janeiro: IBGE, 2008. 203 p.

Instituto de Pesquisa Econômica Aplicada (IPEA). Caracterização e tendências da rede urbana do Brasil: configurações atuais e tendências da rede urbana. IPEA, IBGE, UNICAMP. Brasília: IPEA, 2001.

Ministério da Integração Nacional. Política Nacional de Desenvolvimento Regional. Brasília: SPR/Ministério da Integração Nacional, $\mathrm{s} / \mathrm{d}$.

Ministério da Integração Nacional. I Conferência Nacional de Desenvolvimento Regional - documento de referência. Brasília, 2012. Disponível em: <http://www.integracao.gov.br/web/cndr/publicacoes $>$. Acesso em: 1 nov. 2013.

. Ministério da Integração Nacional. Relatório da Conferência Nacional de Desenvolvimento Regional. Brasília, 2013. Disponível em: <http://www.integracao.gov.br/web/cndr/publicacoes>. Acesso em 1 nov. 2013.

- Ministério do Planejamento, Orçamento e Gestão. Estudo da dimensão territorial do planejamento. Elaborado pelo CEDEPLAR - UFMG. Brasília: 2008.

- Ministério do Planejamento, Orçamento e Gestão. Plano Plurianual PPA 2004 - 2007. Brasília: SPI/Ministério do Planejamento, Orçamento e Gestão, 2004.

- Ministério do Planejamento, Orçamento e Gestão. Plano Plurianual PPA 2008 - 2011. Brasília: SPI/Ministério do Planejamento, Orçamento e Gestão, 2008. 
BRUGUÉ, Q. Transversalidad: del concepto a la práctica, de las ideas a los resultados. Institut de Govern i Polítiques Públiques (IGOP - UAB). Seminário de Gestão Pública. Da eficiência à inteligência: a administração pública deliberativa para a construção de inteligência coletiva na gestão. Anais... Escola Nacional de Administração Pública - Enap, 20 a 21 de junho de 2012.

CAMPOS, Neio; KRAHL, Maria Flora Lottici. Territorialidade: elo entre o espaço rural e o espaço urbano. In: STEINBERGER, Marília (Org.). Território, ambiente e políticas públicas espaciais. Brasília: Paralelo 15 e LGE Ed. 2006, p. 83-100.

CORREIA, Roberto Lobato. Região e organização espacial. São Paulo: Ática, 1991.

MUELLER, Charles Curt. Formação de políticas públicas. Revista de Economia Política, v. 2, n. 5, p-87-122, jan-mar, 1982.

OFFE, Claus. A atual transição da historia e algumas opções básicas para as instituições da sociedade. In: PEREIRA, Luis Carlos Bresser; WILHEIM, Jorge; SOLA, Lourdes (Orgs.). Sociedade e Estado em transformação. São Paulo/Brasília: EDUNESP/ENAP, 1999.

SANTOS, Milton. Técnica, tempo, espaço: globalização e meio técnicocientífico-informacional. São Paulo: Hucitec, 2002.

. Metamorfose do espaço habitado. São Paulo: Hucitec, 1991.

SOJA, Edward. Geografias pós-modernas: a reafirmação do espaço na teoria social. Rio de Janeiro: Jorge Zahar, 1993.

STEINBERGER, Marília. A inseparabilidade entre Estado, políticas públicas e território. In: STEINBERGER, Marília (Org.). Território, Estado e políticas públicas espaciais. Brasília: Ler Ed. 2013, p. 31-64.

SUNKEL, Osvaldo. Globalização, neoliberalismo e a reforma do Estado. In: PEREIRA, Luis Carlos Bresser; WILHEIM, Jorge; SOLA, Lourdes (Orgs.). Sociedade e Estado em transformação. São Paulo/Brasília: EDUNESP/ENAP, 1999. 
Endereço para correspondência:

Adriana Melo Alves - adriana.alves@integracao.gov.br Quadra 906, Módulo F, Bloco A, Edifício Celso Furtado, Sala 203 70.790-060 Brasília/DF, Brasil

João Mendes da Rocha Neto - joao.neto@integracao.gov.br Quadra 906, Módulo F, Bloco A, Edifício Celso Furtado, Sala 218 70.790-060 Brasília/DF, Brasil

Paulo Pitanga do Amparo - paulo.amparo@integracao.gov.br Quadra 906, Módulo F, Bloco A, Edifício Celso Furtado, Sala 216 70.790-060 Brasília/DF, Brasil 